Supplement of Geosci. Model Dev., 14, 3437-3472, 2021

https://doi.org/10.5194/gmd-14-3437-2021-supplement

(C) Author(s) 2021. CC BY 4.0 License.

(c) (i)

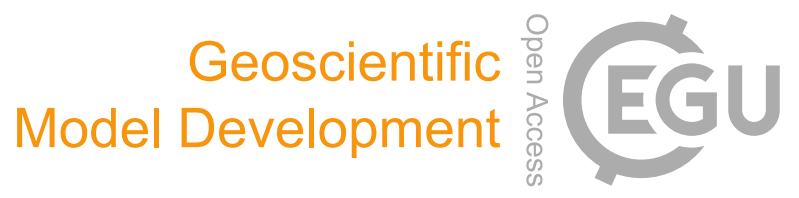

Supplement of

\title{
Evaluating the physical and biogeochemical state of the global ocean component of UKESM1 in CMIP6 historical simulations
}

\author{
Andrew Yool et al. \\ Correspondence to: Andrew Yool (axy@noc.ac.uk) and Julien Palmiéri (julien.palmieri@noc.soton.ac.uk)
}

The copyright of individual parts of the supplement might differ from the article licence. 


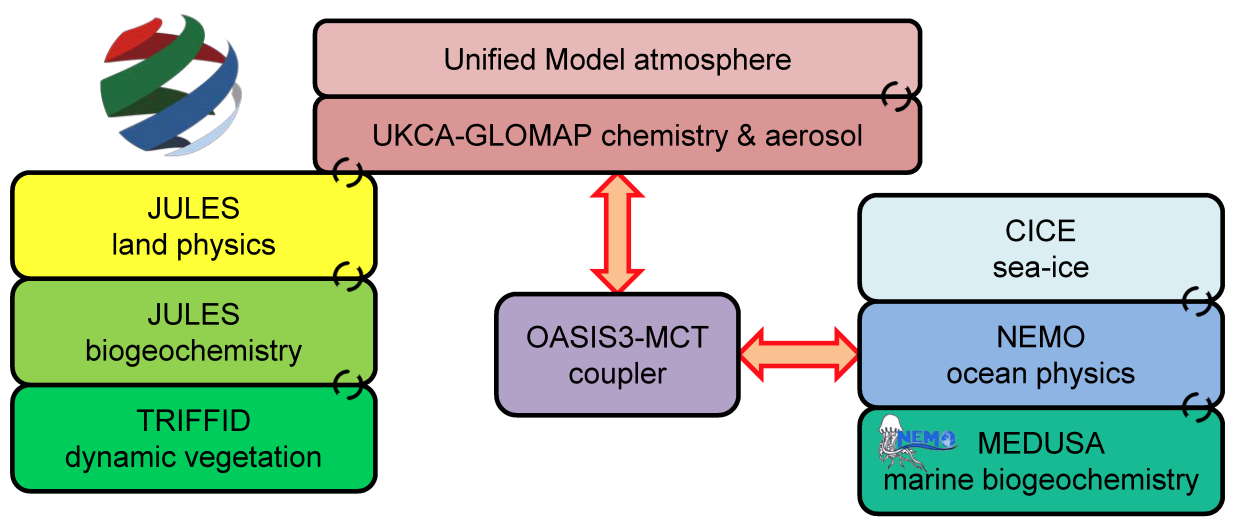

Figure S1. Schematic diagram of the components of UKESM1 and the associated code structuring and coupling relationships. Circular arrows indicate couplings between closely associated component codes, while large arrows indicate couplings between separate and distinct component codes (principally the atmosphere and ocean). 


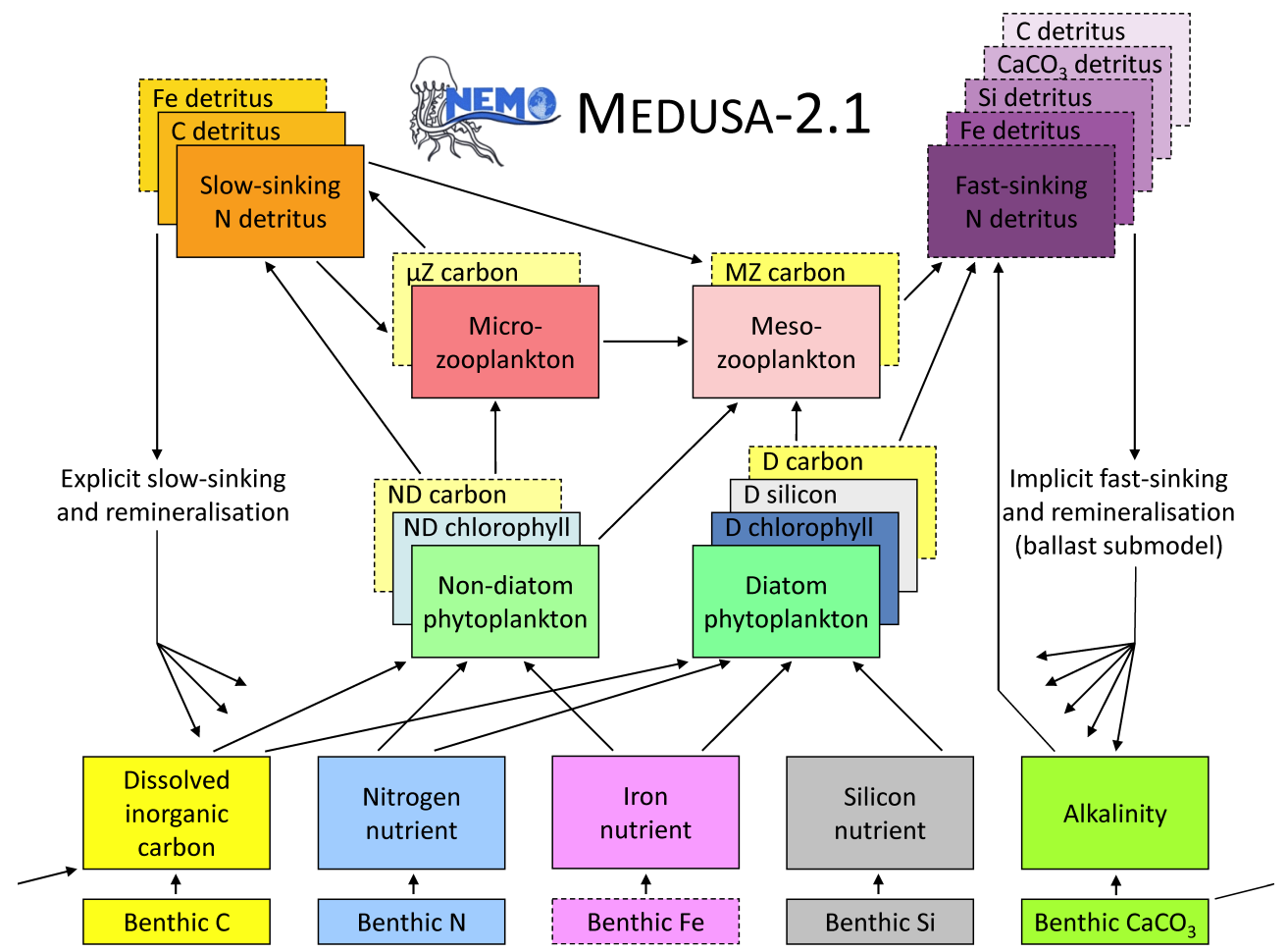

Figure S2. Schematic diagram of the MEDUSA-2.1 marine biogeochemistry model, showing both its components and their linkages. The model includes the biogeochemical cycles of nitrogen, silicon, iron, carbon, alkalinity and oxygen in a dual size class nutrient-phytoplanktonzooplankton-detritus framework. Components with solid borders are those explicitly represented as passive tracers in MEDUSA-2.1, while those with dashed borders are implicit to reduce model cost. These are either linked via rigid stoichiometry to explicit components (e.g. carbon in plankton) or occur only temporarily (e.g. fast-sinking detritus). Oxygen has been omitted from the diagram for simplicity. 

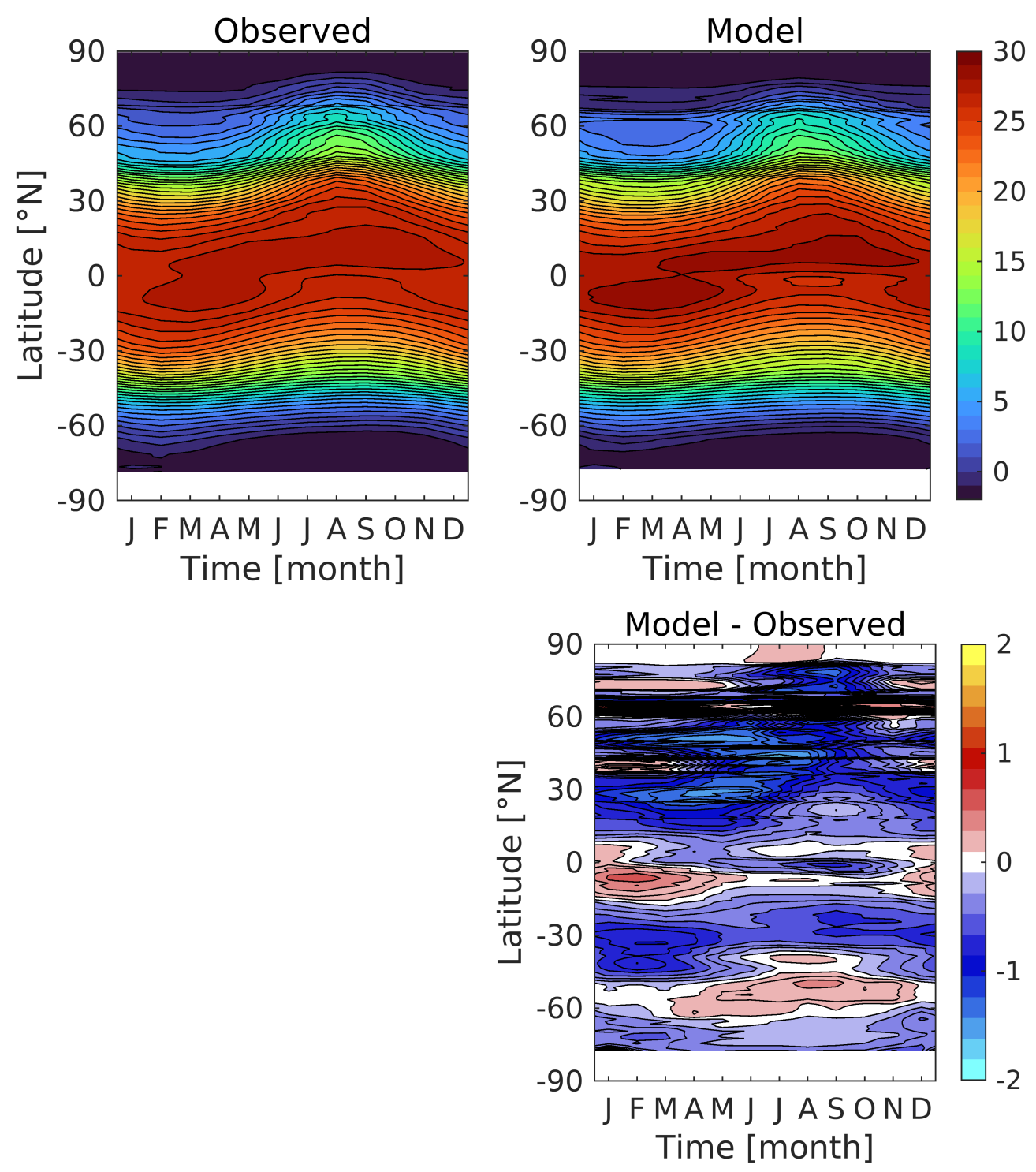

Figure S3. Zonal Hovmöller diagrams of observed (HadISST; top left), simulated (top right), and difference (simulated - observed; bottom right). Temperature (and difference in temperature) in ${ }^{\circ} \mathrm{C}$. 
Difference, JJA, 1970s

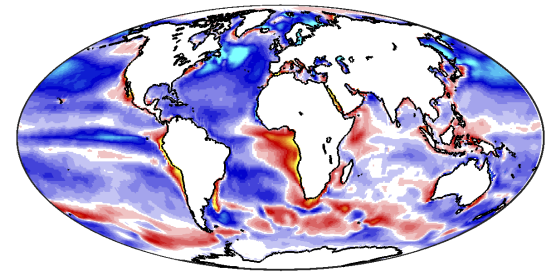

Difference, JJA, 1980s

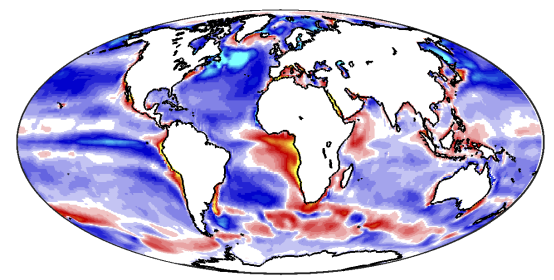

Difference, JJA, 1990s

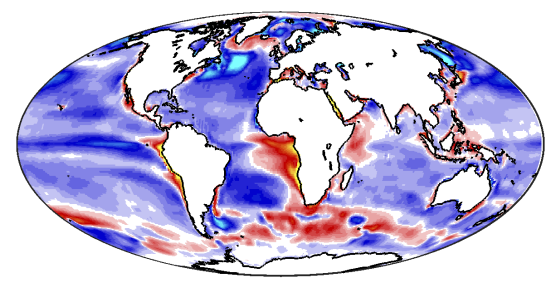

Difference, JJA, 2000s

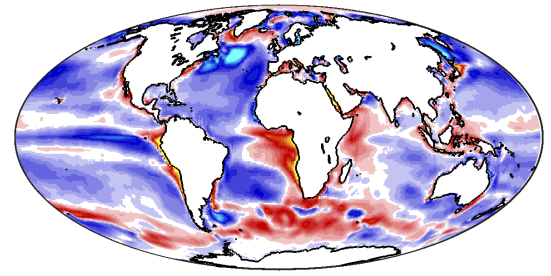

Difference, DJF, 1970s

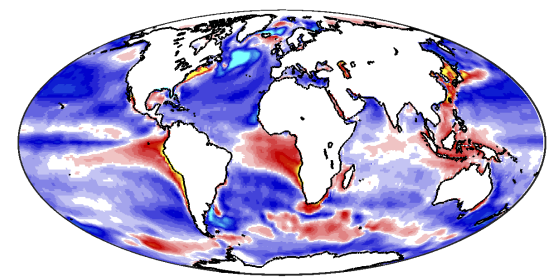

Difference, DJF, 1980s

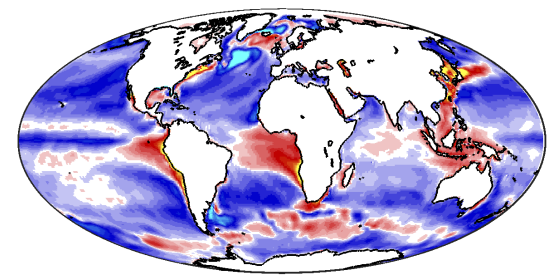

Difference, DJF, 1990s

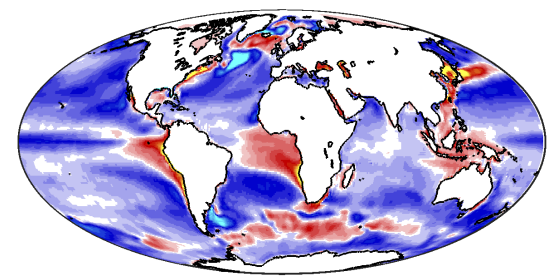

Difference, DJF, 2000s

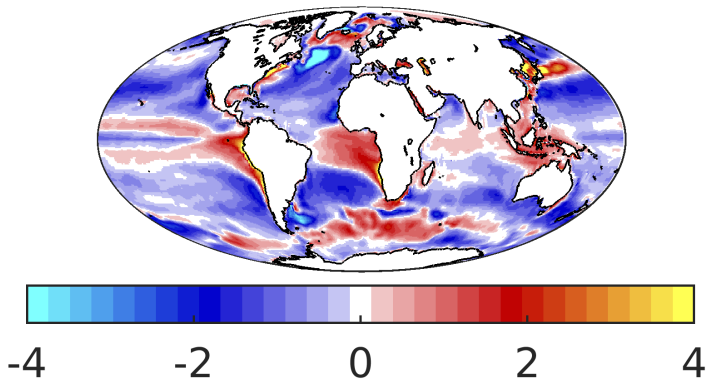

Figure S4. Following on from Figure 1, the panels above show differences in SST (simulated - observed) for JJA and DJF seasons for four decadal periods from the 1970 s to the 2000s. In each case the difference shown is the observational climatology for the decade subtracted from the simulated ensemble mean climatology for the same period. The final panel reproduces the difference figure for the standard analysis window of 2000-2009 used in Figure 1. Difference in temperature in ${ }^{\circ} \mathrm{C}$. 

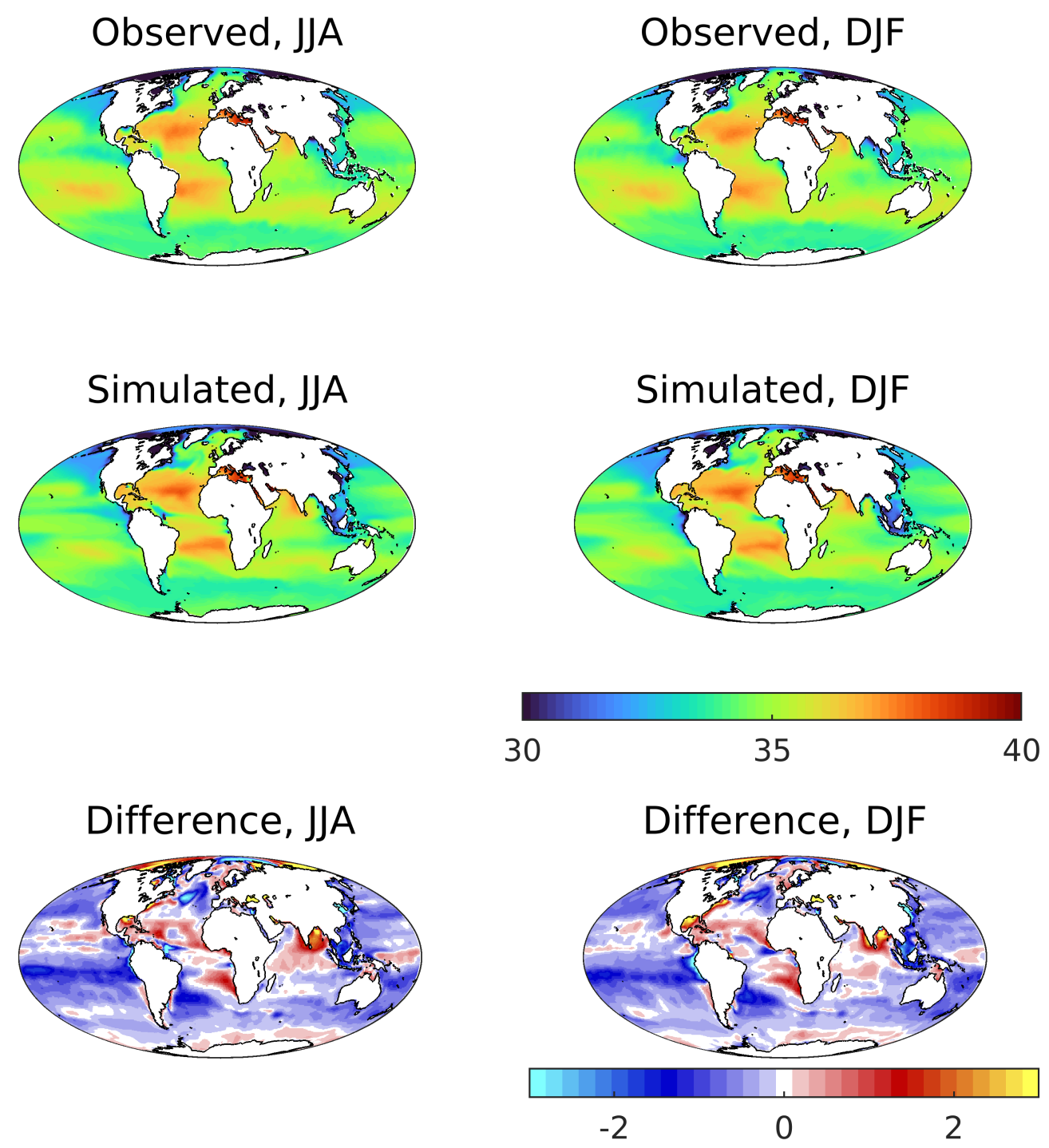

Figure S5. Observational (WOA, 2013) and simulated sea surface salinity for northern (top; JJA) and southern (medium; DJF) summer. Differences (simulated - observed) for both seasons shown in the bottom row. Salinity (and difference in salinity) in PSU. 
Observed, March

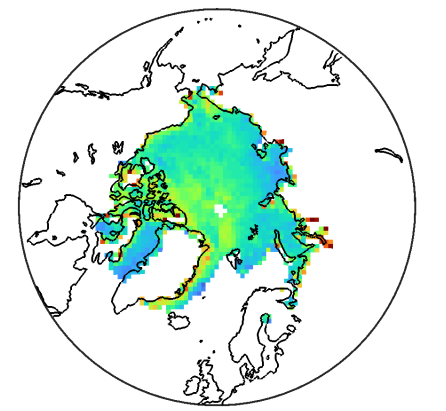

Simulated, March

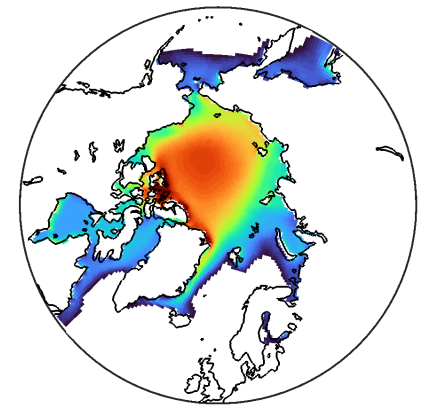

Observed, September

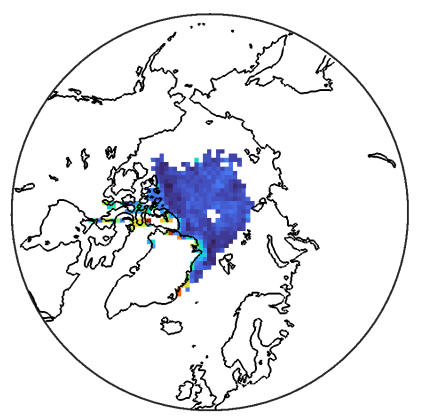

Simulated, September

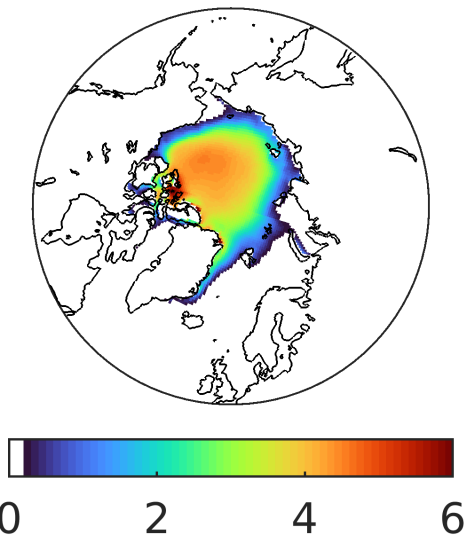

Figure S6. Observational (left; NSIDC) and simulated (right) maximum (top; March) and minimum (bottom; September) sea-ice thickness for the Arctic. Model sea-ice thicknesses of less than $0.1 \mathrm{~m}$ have been masked. Sea-ice thickness is in $\mathrm{m}$. 

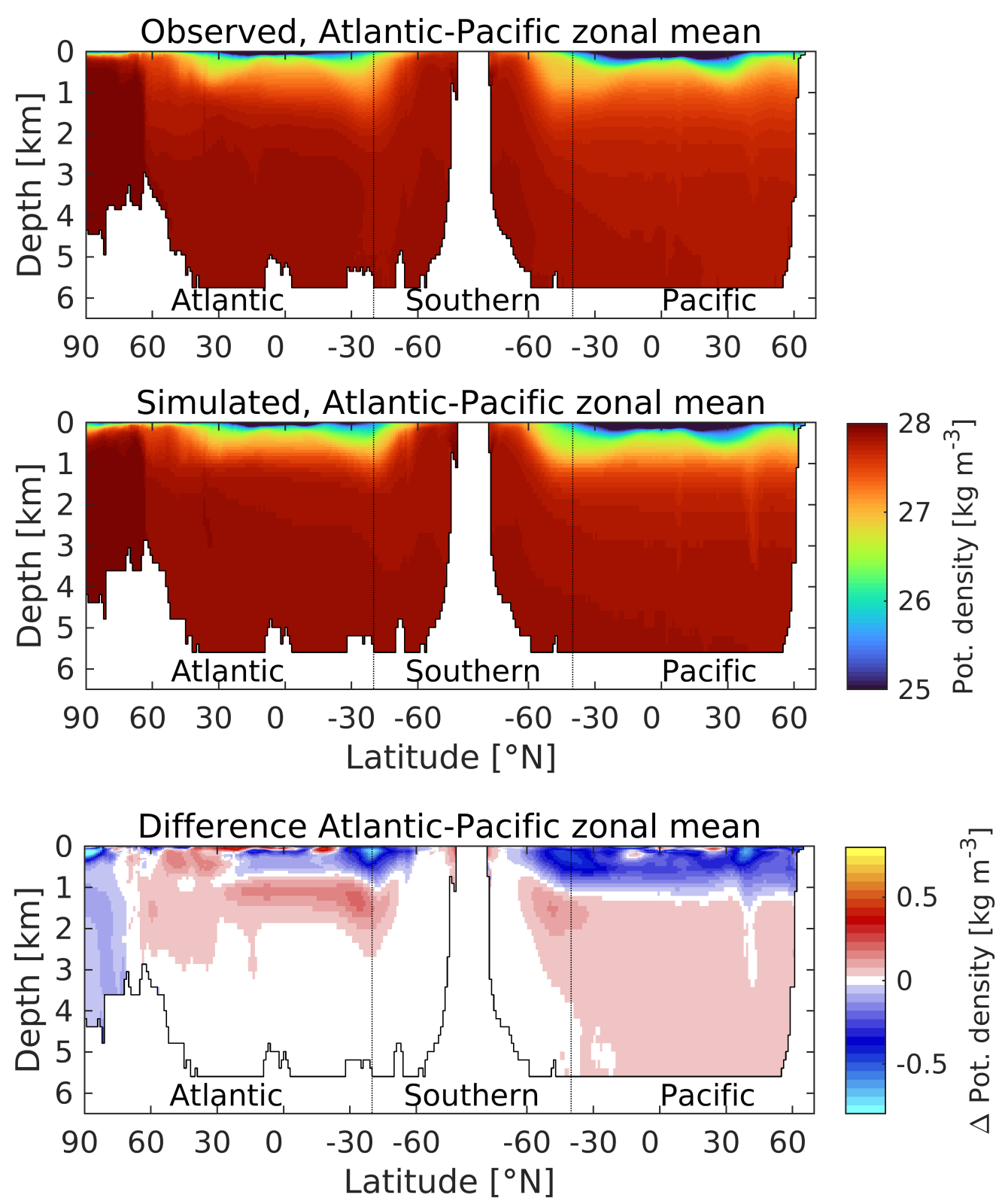

Figure S7. A "thermohaline circulation" section of observed (top) and modelled (middle) zonal potential density anomaly ( $\sigma_{\theta}$; referenced to atmospheric pressure). Difference (simulated - observed) is shown in the bottom panel. Potential density is shown as kg $\mathrm{m}^{-3} \mathrm{minus} 1000$ $\mathrm{kg} \mathrm{m}^{-3}$ (i.e. the actual density range in the upper panels is 1025 to $1028 \mathrm{~kg} \mathrm{~m}^{-3}$ ). Figure 6 explains the format of this section. 


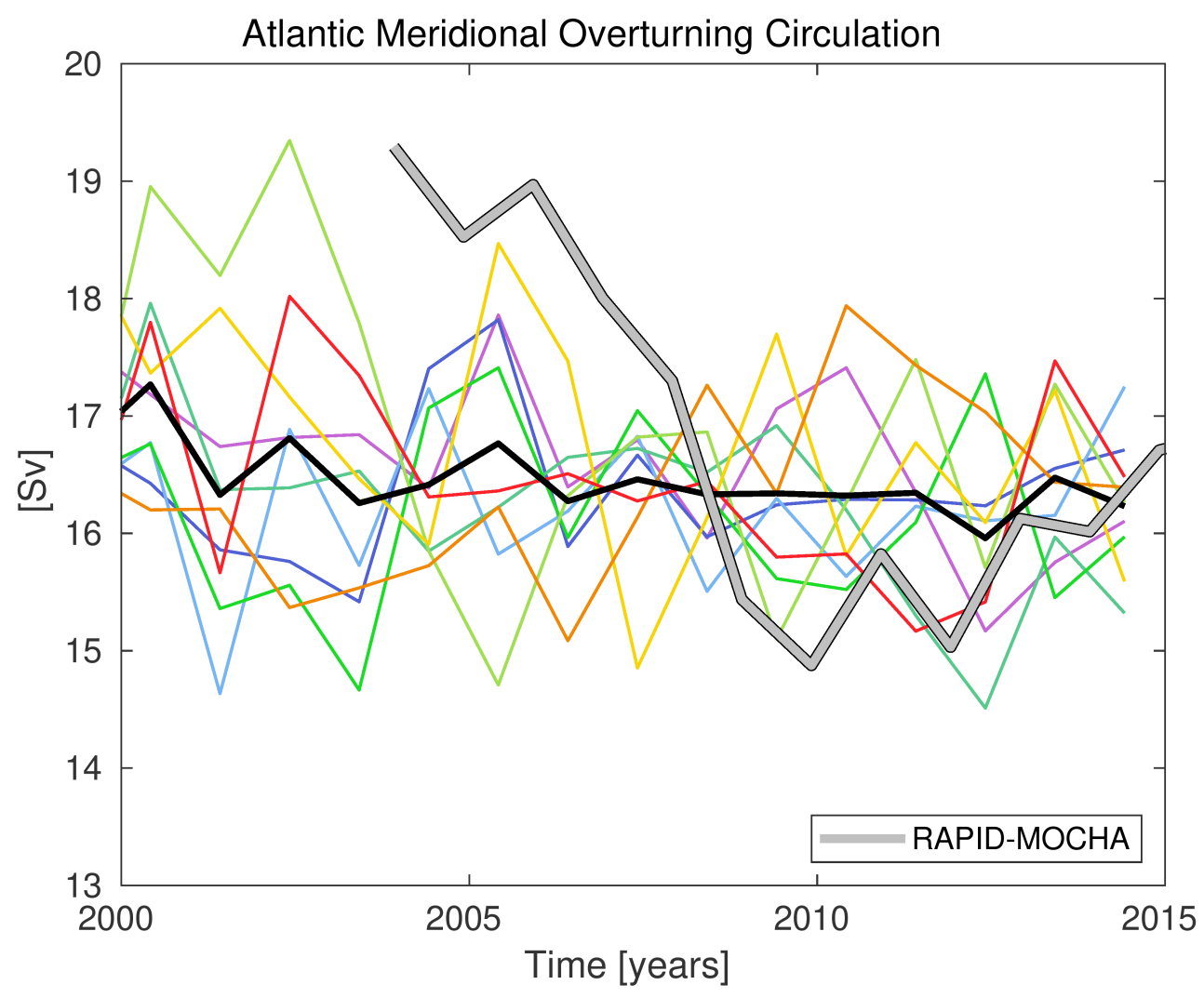

Figure S8. Time-series plot of AMOC transport during a focused section of the Historical period from 2000 to 2015 . The panel shows annual averages of AMOC transport for all 9 ensemble members (coloured lines), the ensemble mean (solid black line), and observational data from the RAPID-MOCHA array (grey; 2003-2015). The time-series of AMOC transport across the full Historical period is shown in Figure 9. 

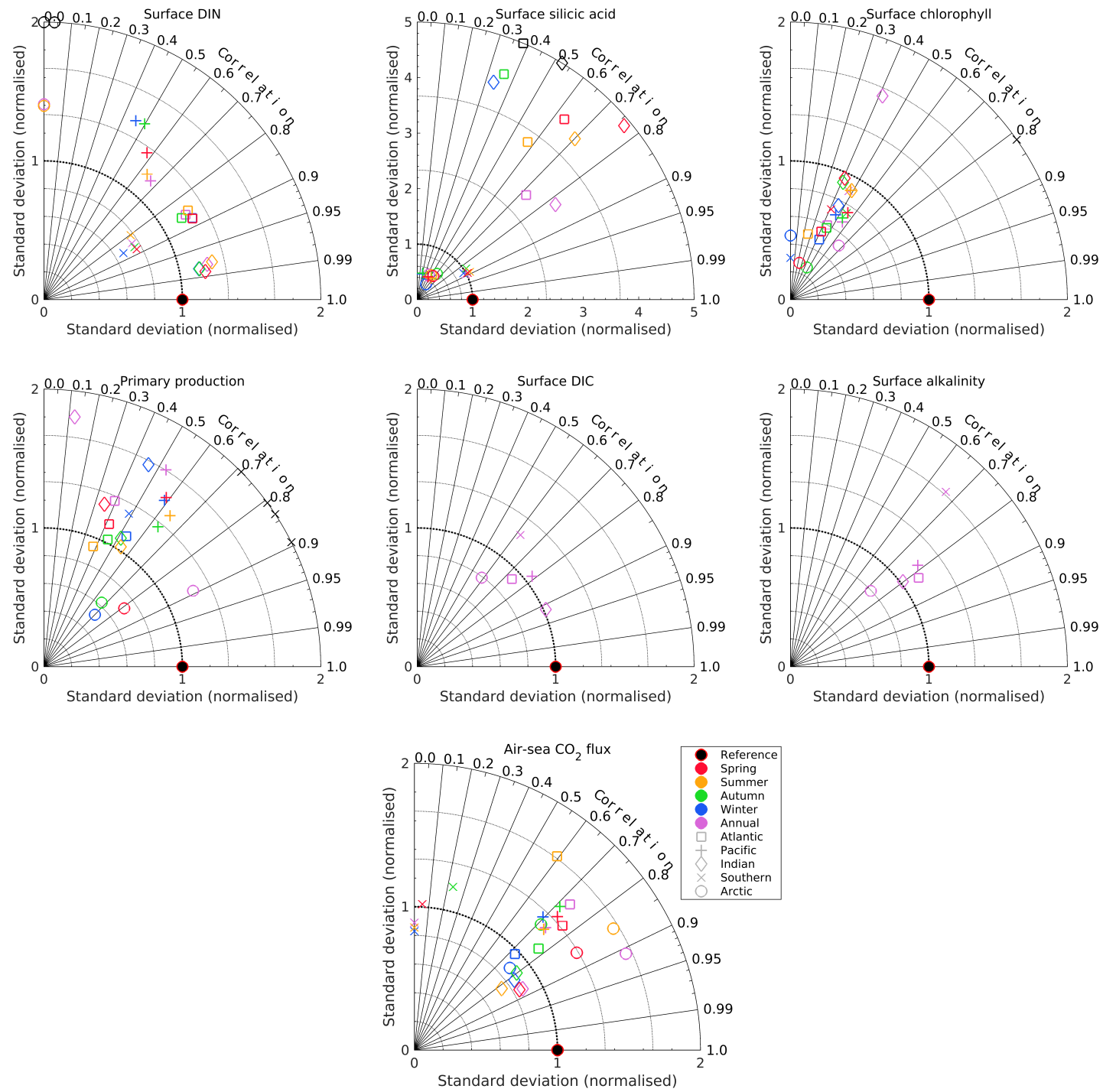

Figure S9. Taylor diagrams illustrating the seasonal and regional skill of UKESM1 over the set of standard surface ocean of biogeochemical properties: DIN (row 1, left), silicic acid (row 1, centre), chlorophyll (row 1, right), primary production (row 2, left), DIC (row 2, centre), alkalinity (row 2, right) and air-sea $\mathrm{CO}_{2}$ flux (row 3). The diagrams share a common model key (row 3). Black symbols denote skill scores that lie outside of the plot range. 


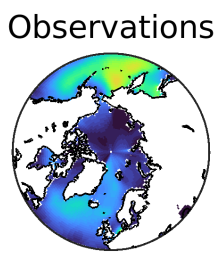

HadGEM2-ES

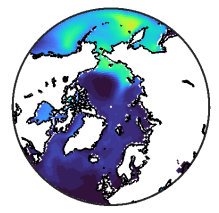

CanESM5

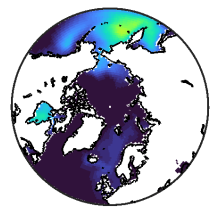

MPI-ESM1-2-LR

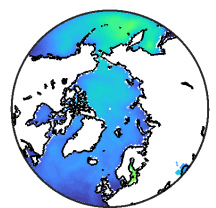

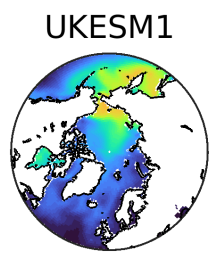

CESM2-FV2

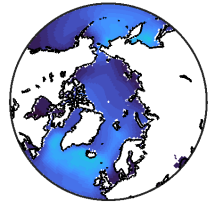

IPSL-CM6A-LR

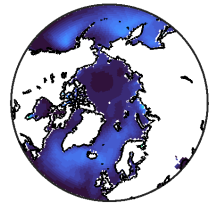

MRI-ESM2-0

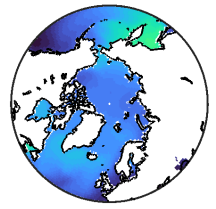

MEDUSA-2

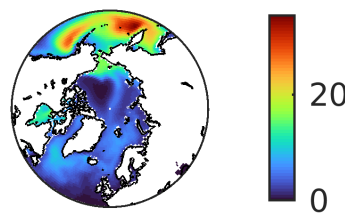

CNRM-ESM2-1

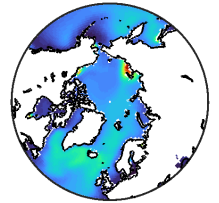

MIROC-ES2L

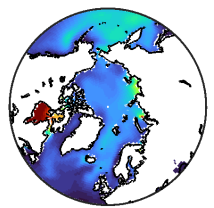

NorESM2-LM

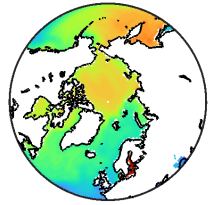

Figure S10. Intercomparison of annual mean surface dissolved inorganic nitrogen concentration (CMOR variable no3) in the Arctic between observed (top row, left), UKESM1 simulated (top row, centre) and a range of comparable CMIP6 models (rows 2-4). DIN concentration in mmol N m${ }^{-3}$. Previously published results from MEDUSA-2 (Yool et al., 2013) are shown for comparison (top row, right). DIN concentration in $\mathrm{mmol} \mathrm{N} \mathrm{m}^{-3}$. 


\section{Pn summer limitation}

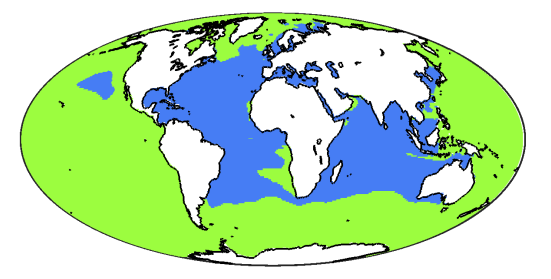

\section{Pd summer limitation}

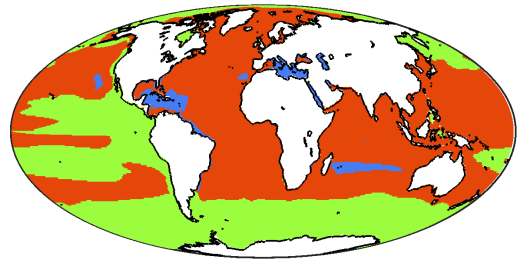

N

$\mathrm{Fe}$

$\mathrm{Si}$

Figure S11. Simulated patterns of most-limiting nutrient for non-diatom (left; N and Fe) and diatom (right; N, Si and Fe) phytoplankton. Limitation is summertime mean, weighted by biomass and integrated for the full water column. 

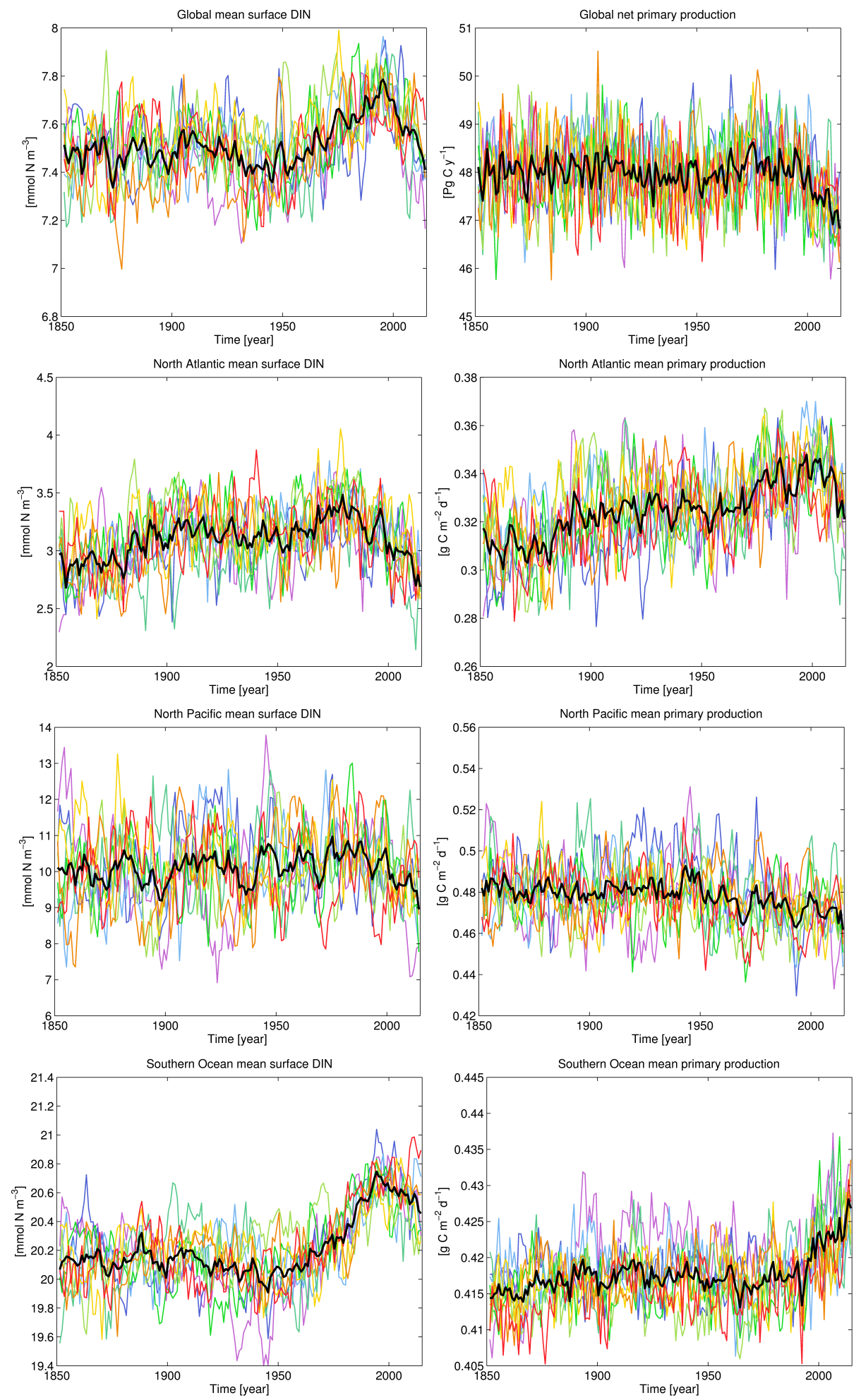

Figure S12. Time-series plots of mean surface DIN (left) and vertically-integrated primary production (right) during the Historical period from 1850 to 2015. Time-series are shown for global (row 1), North Atlantic (row 2), North Pacific (row 3) and Southern Ocean (row 4) regions. Panels show annual averages for all 9 ensemble members (coloured lines) and the ensemble mean (solid black line). 

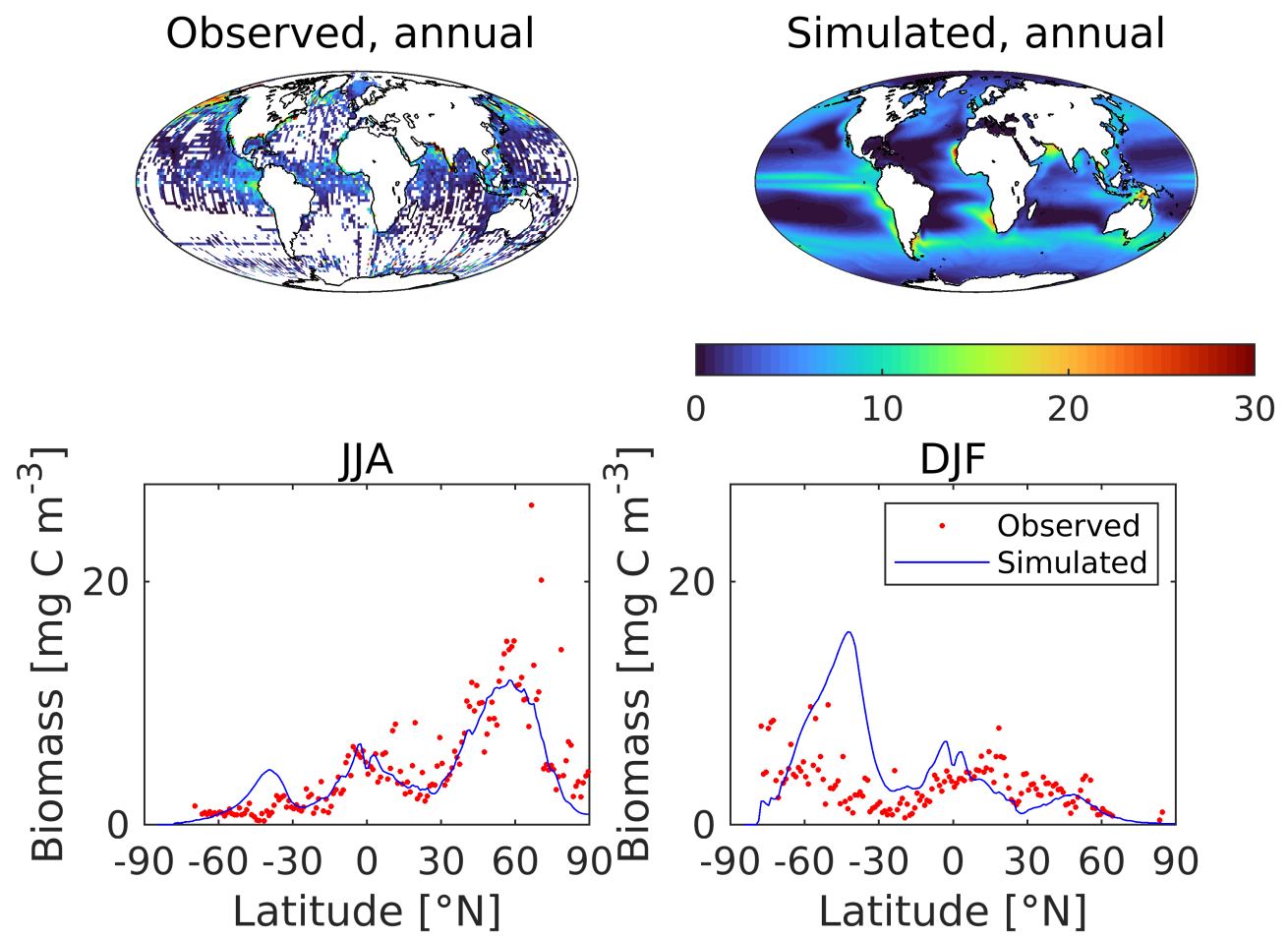

Figure S13. Annual mean observed (top left) and simulated (top right) mesozooplankton biomass, together with latitudinal averages for northern summer (bottom left; JJA) and southern summer (bottom right; DJF). Concentrations in $\mathrm{mg} \mathrm{C} \mathrm{m}^{-3}$. 

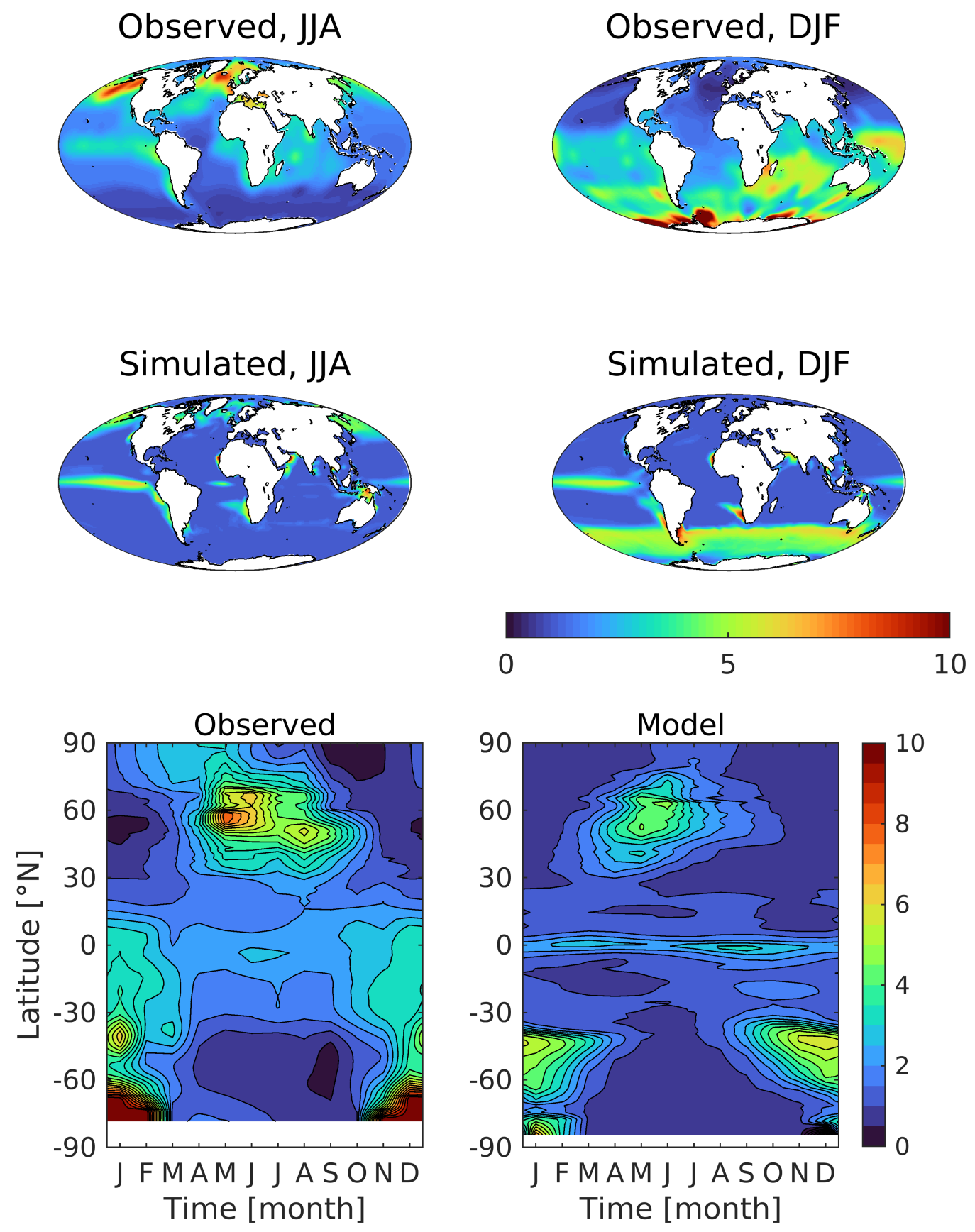

Figure S14. Observed (left; Lana et al. (2011)) and simulated (right) surface dimethylsulfide concentration, shown geographically for northern (top; JJA)and southern summer (middle; DJF), and as zonal Hovmöller diagrams (bottom). DMS concentration in $\mu$ mol S m ${ }^{-3}$. 

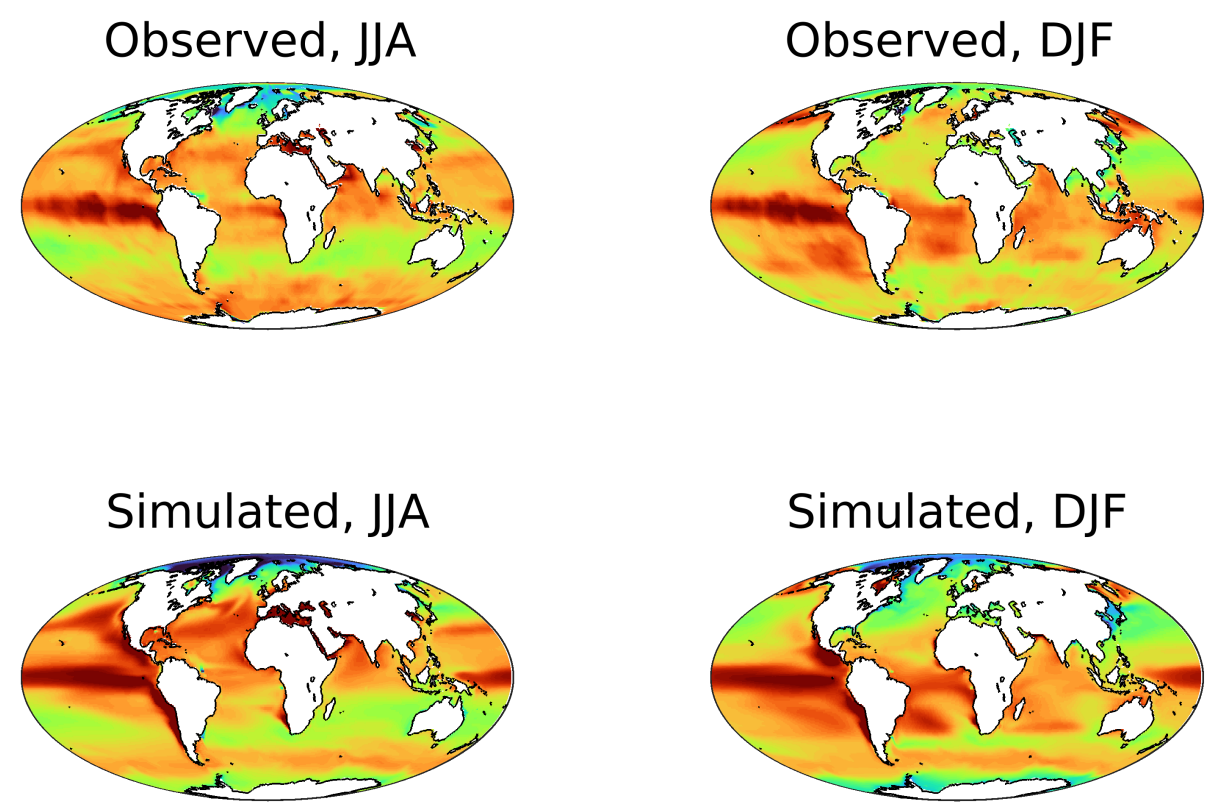

\section{Simulated, DJF}
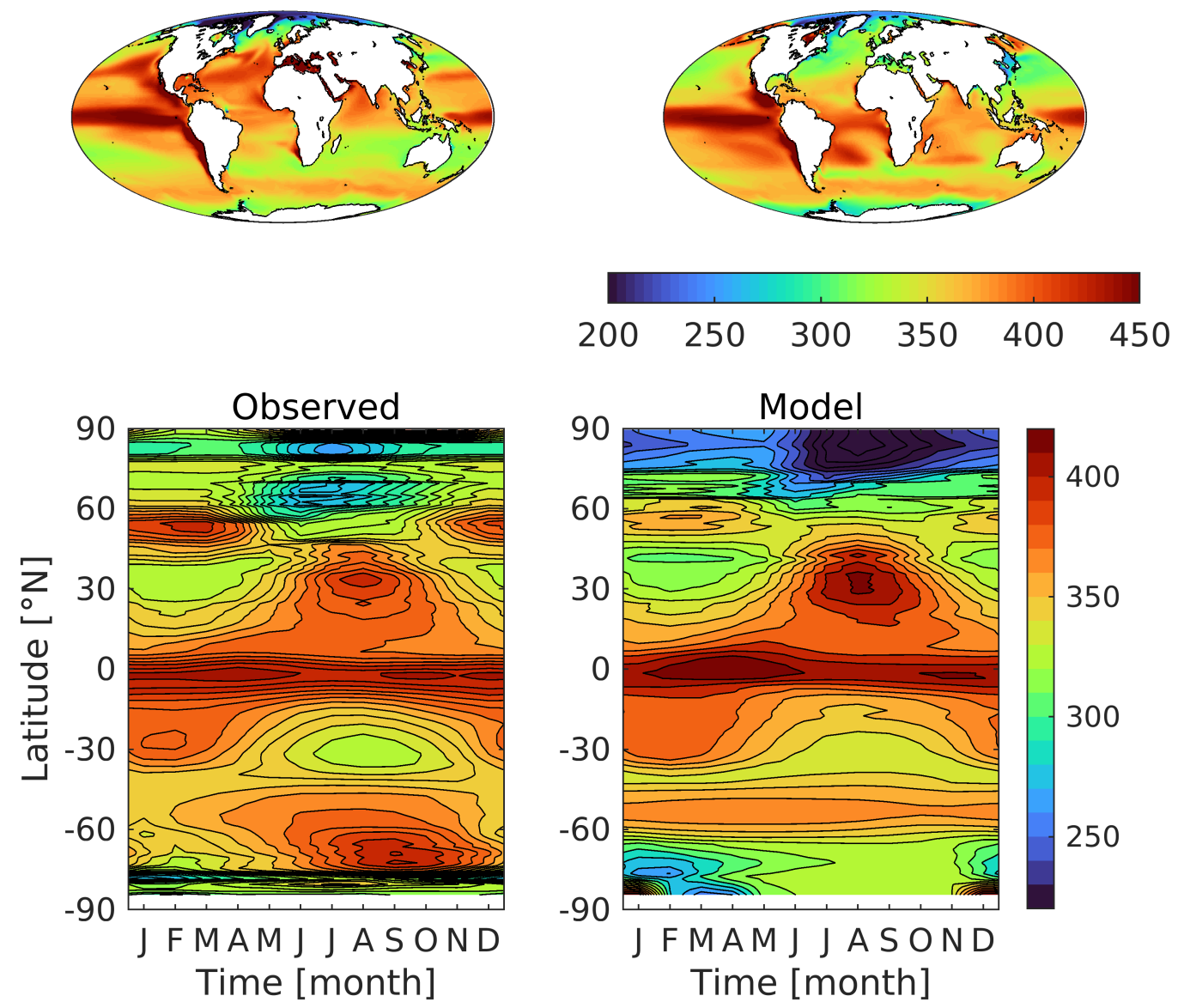

Figure S15. Observed (left; Rödenbeck et al. (2013)) and simulated (right) surface carbon dioxide partial pressure, shown geographically for northern (top; JJA)and southern summer (middle; DJF), and as zonal Hovmöller diagrams (bottom). $\mathrm{pCO}_{2}$ in $\mu$ atm. 

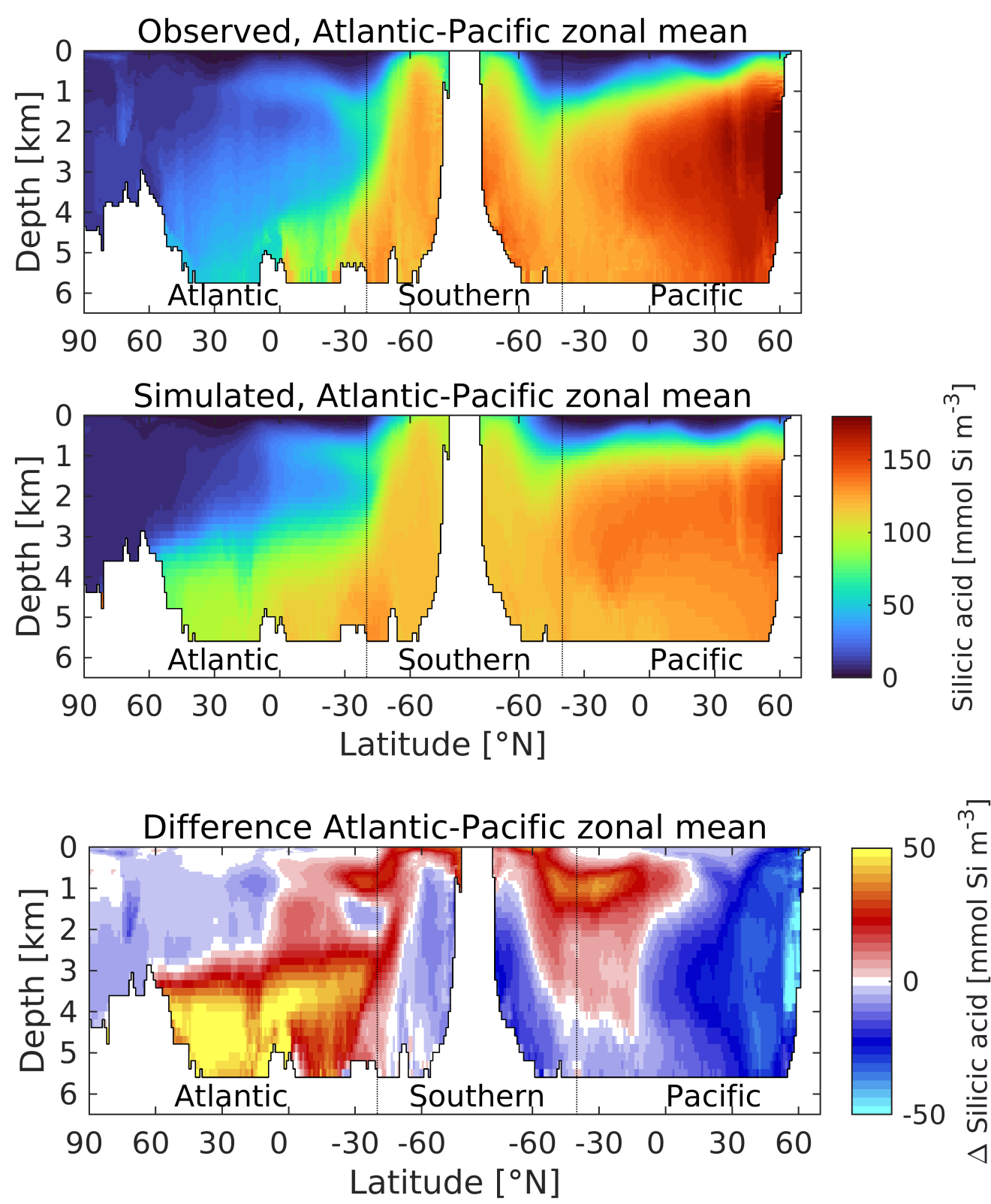

Figure S16. A "thermohaline circulation" section of observed (top) and modelled (middle) zonal average silicic acid. Difference (simulated - observed) is shown in the bottom panel. Concentrations in mmol $\mathrm{Si} \mathrm{m}^{-3}$. Figure 6 explains the format of this section. 

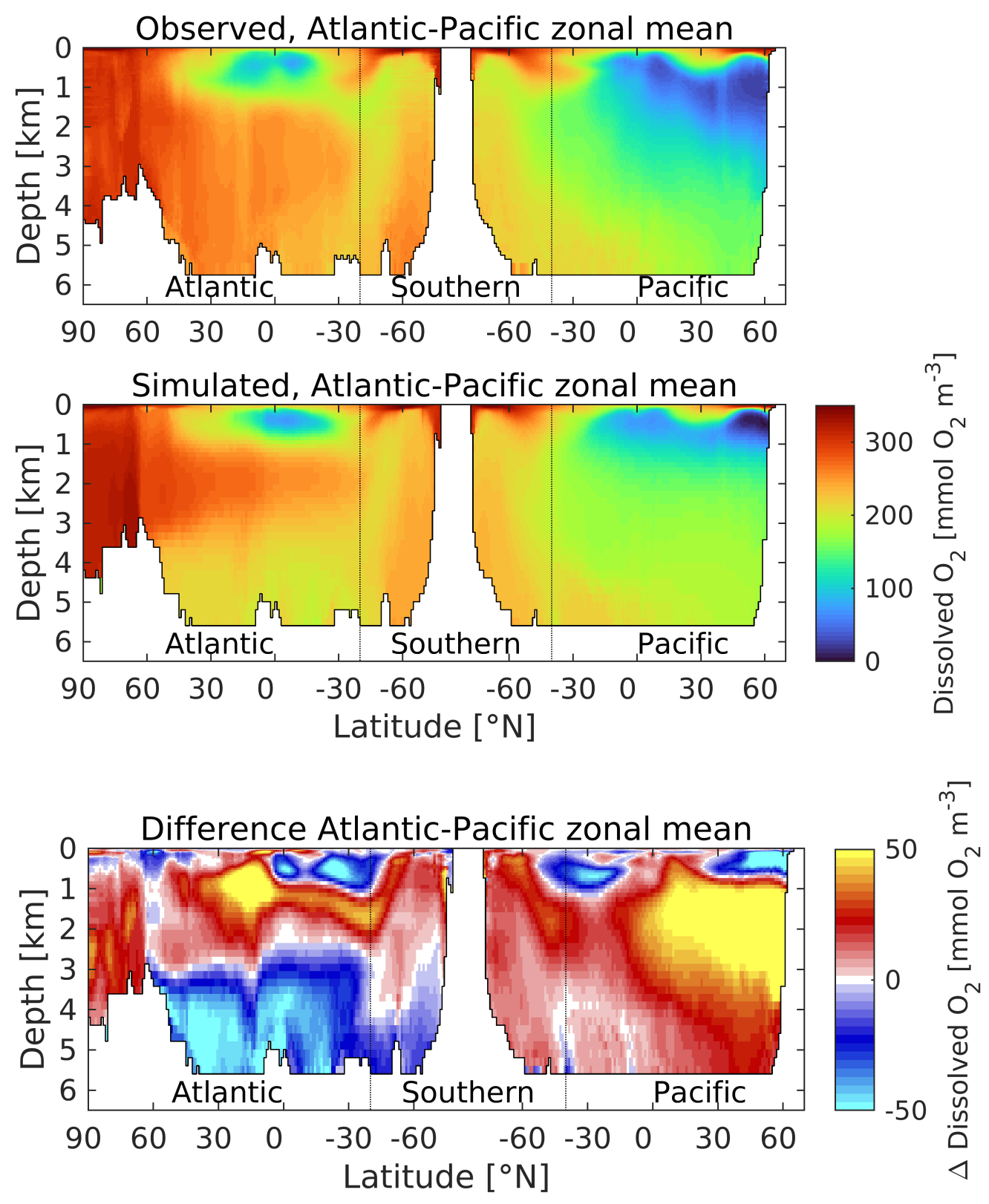

Figure S17. A "thermohaline circulation" section of observed (top) and modelled (middle) zonal average dissolved oxygen. Difference (simulated - observed) is shown in the bottom panel. Concentrations in mmol $\mathrm{O}_{2} \mathrm{~m}^{-3}$. Figure 6 explains the format of this section. 

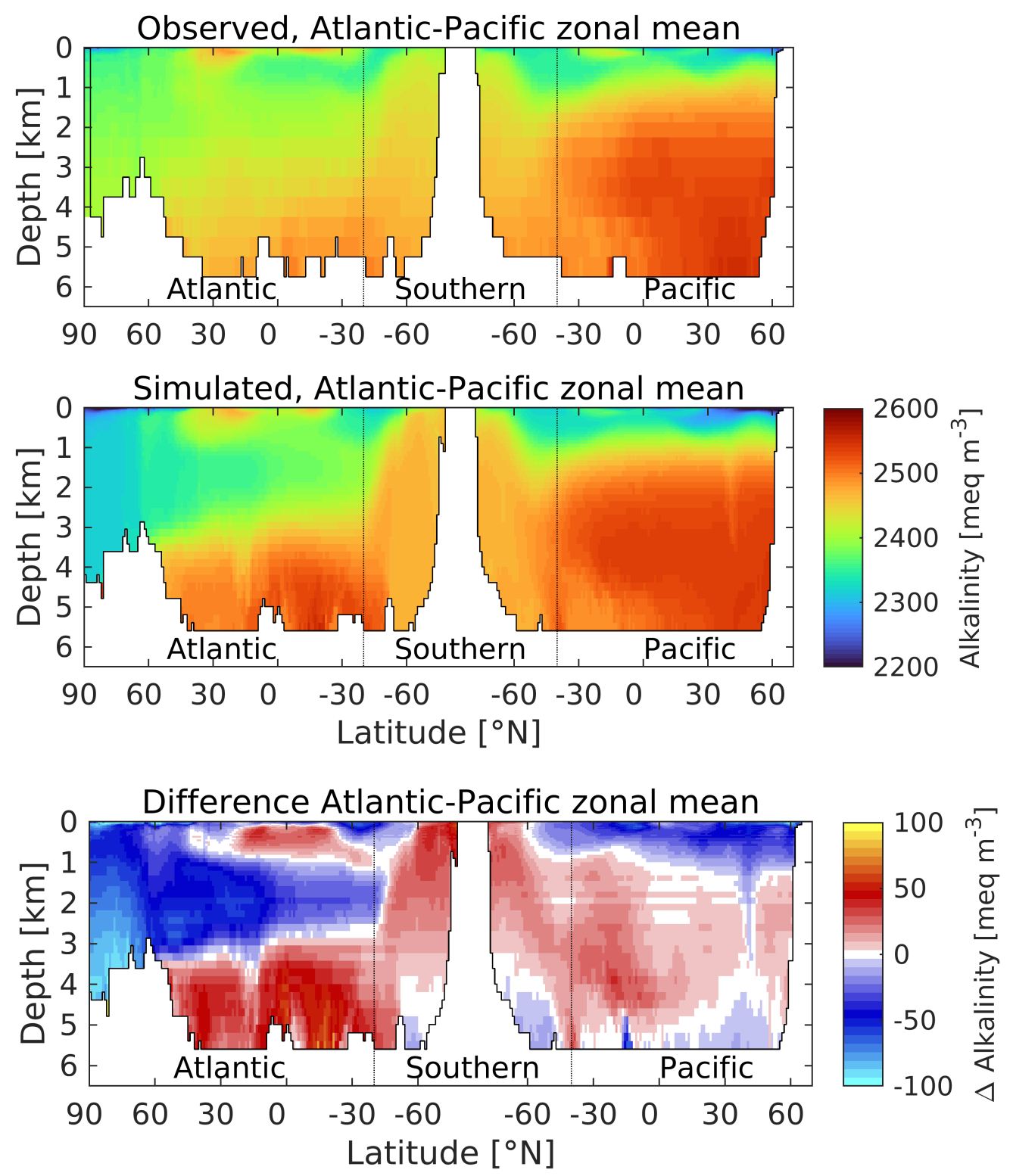

Figure S18. A "thermohaline circulation" section of observed (top) and modelled (middle) zonal average alkalinity. Difference (simulated observed) is shown in the bottom panel. Concentrations in meq $\mathrm{m}^{-3}$. Figure 6 explains the format of this section. 

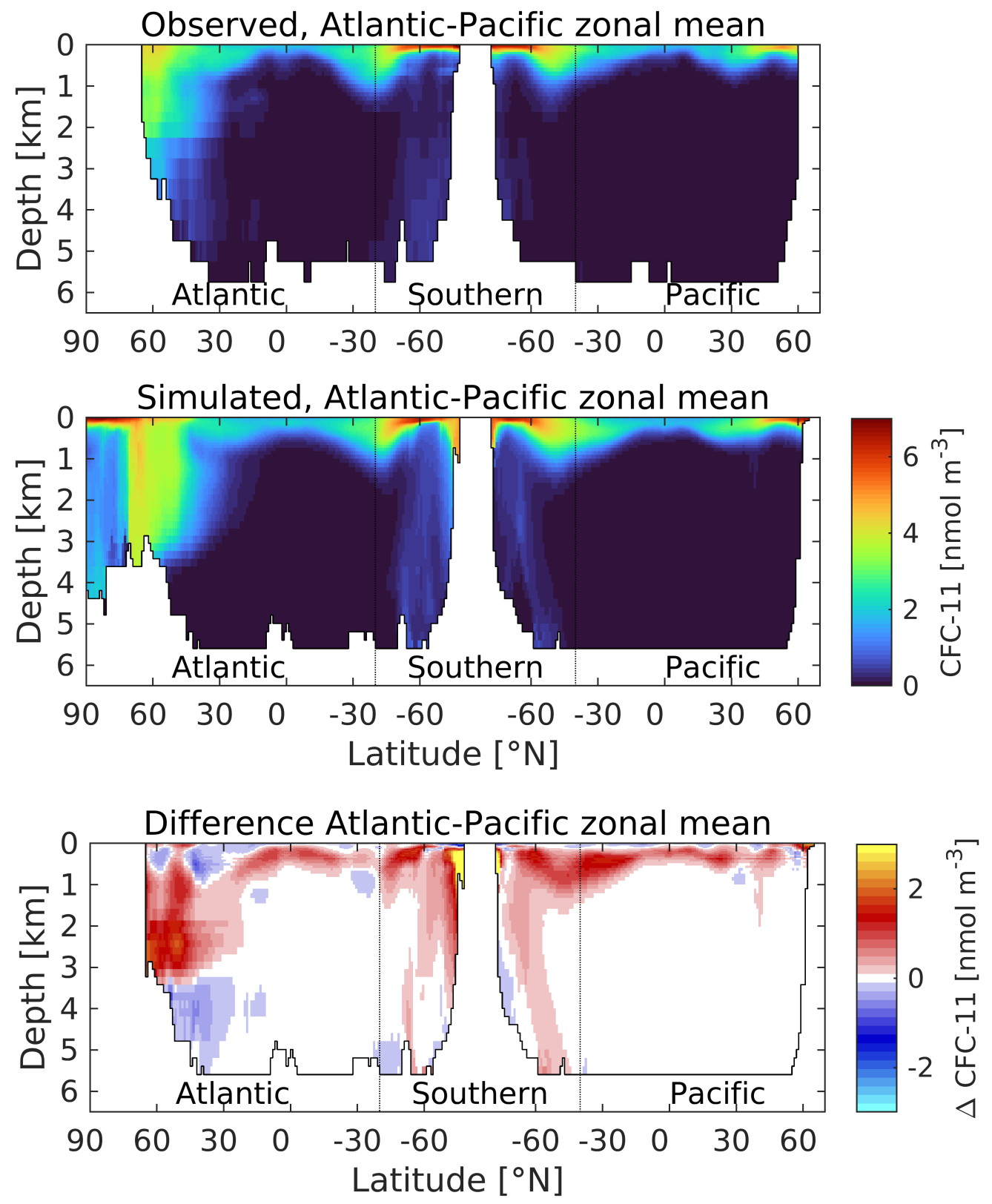

Figure S19. A “thermohaline circulation" section of observed (top) and modelled (middle) zonal average CFC-11. Difference (simulated observed) is shown in the bottom panel. Concentrations in $\mathrm{nmol} \mathrm{m}^{-3}$. Figure 6 explains the format of this section. 


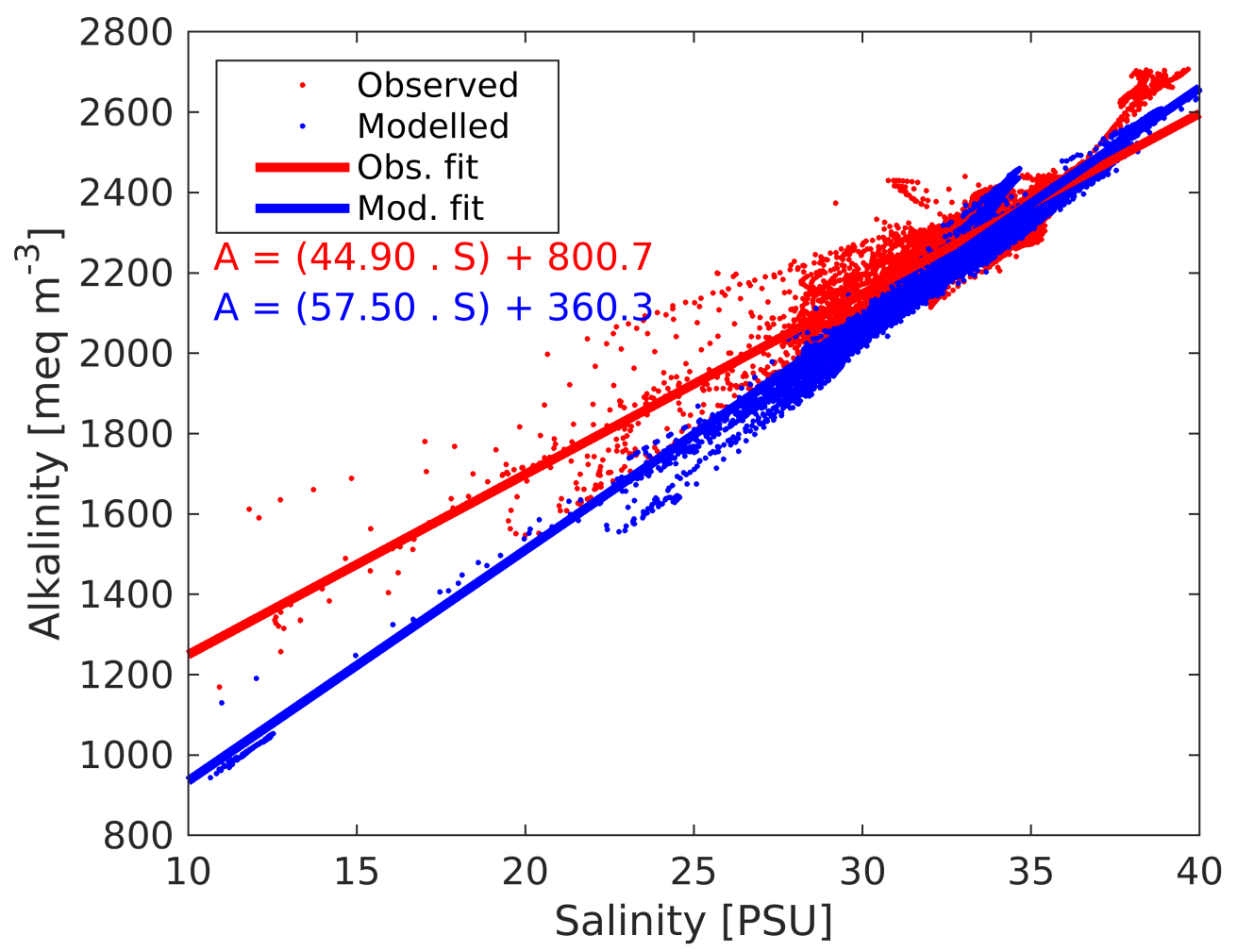

Figure S20. Surface alkalinity plotted against surface salinity for observations (red dots) and model (blue dots). Lines are corresponding linear regressions, with equations shown below legend. Salinity in PSU, alkalinity in meq $\mathrm{m}^{-3}$. 


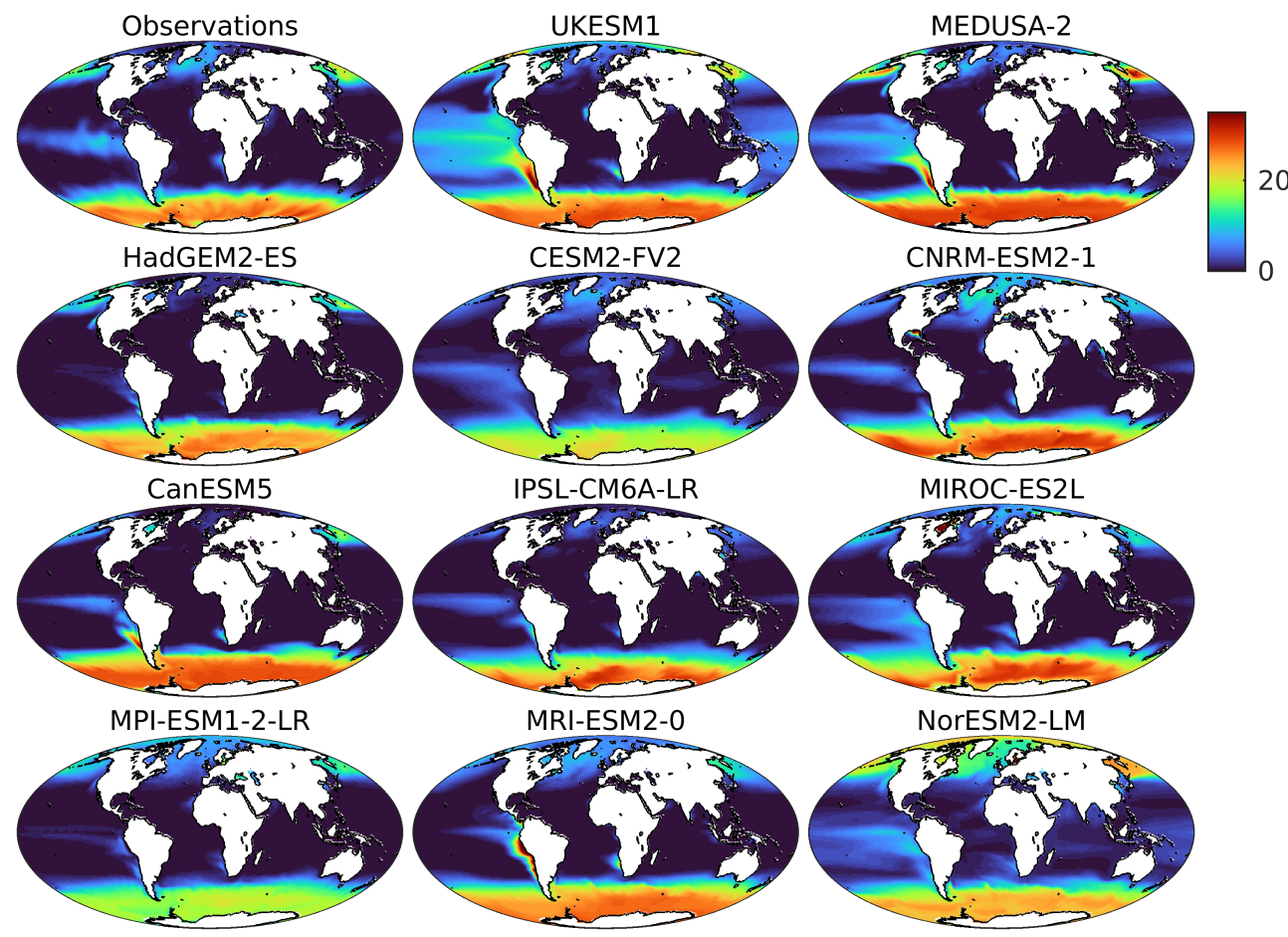

Figure S21. Intercomparison of annual mean surface dissolved inorganic nitrogen concentration (CMOR variable no3) between observed (top row, left), UKESM1 simulated (top row, centre) and a range of comparable CMIP6 models (rows 2-4). Results from CMIP5's precursor to UKESM1, HadGEM2-ES (Jones et al., 2011; row 2, left) and MEDUSA-2 (Yool et al., 2013; top row, right) are shown for comparison. DIN concentration in $\mathrm{mmol} \mathrm{N} \mathrm{m}^{-3}$. 

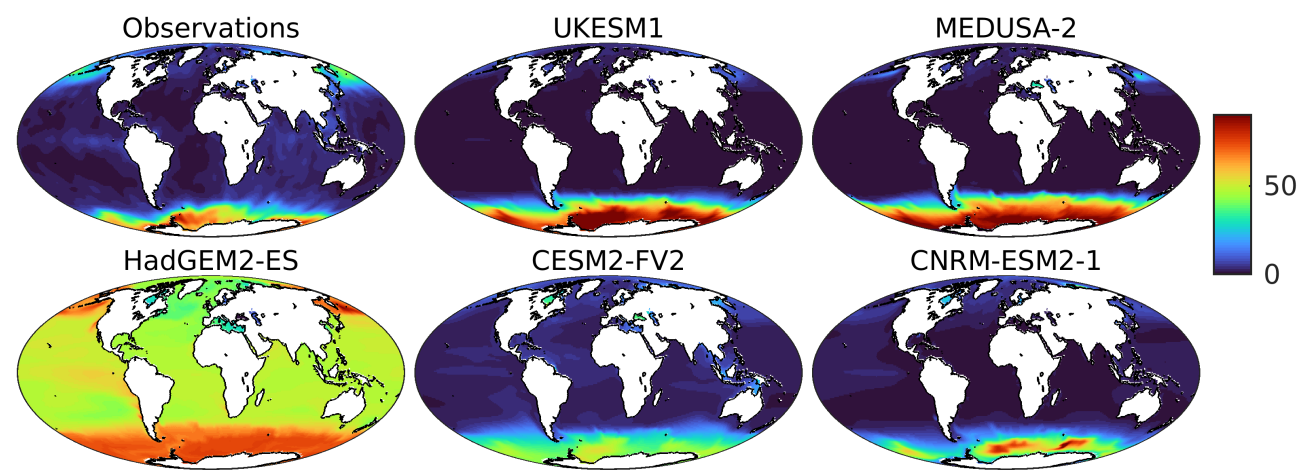

CanESM5

IPSL-CM6A-LR
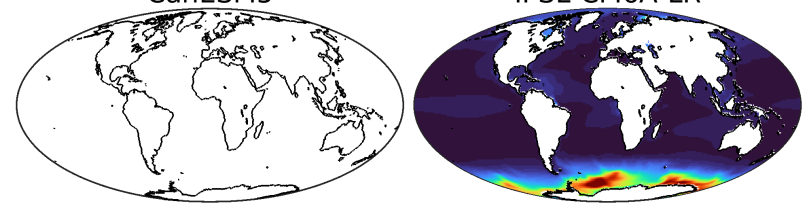

MIROC-ES2L

MPI-ESM1-2-LR
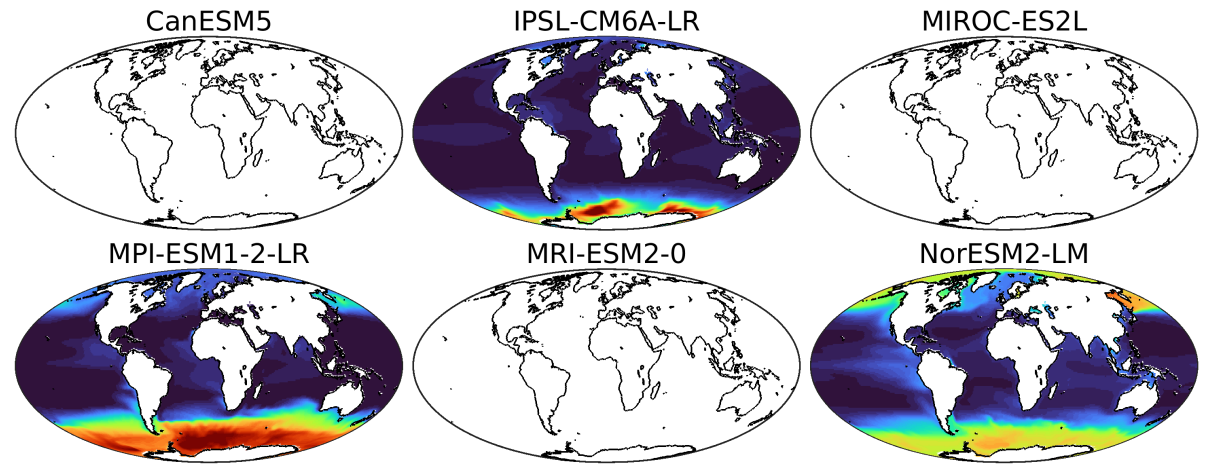

NorESM2-LM

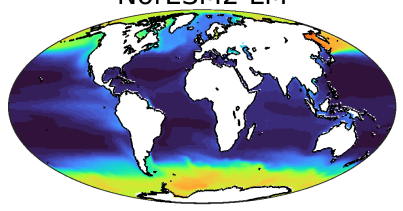

Figure S22. Intercomparison of annual mean surface silicic acid concentration (CMOR variable si) between observed (top row, left), UKESM1 simulated (top row, centre) and a range of comparable CMIP6 models (rows 2-4). Results from CMIP5's precursor to UKESM1, HadGEM2-ES (Jones et al., 2011; row 2, left) and MEDUSA-2 (Yool et al., 2013; top row, right) are shown for comparison. This field was not available for the CanESM5, MIROC-ES2L and MRI-ESM2-0 models and these have been left blank. Silicic acid concentration in mmol Si m ${ }^{-3}$. 


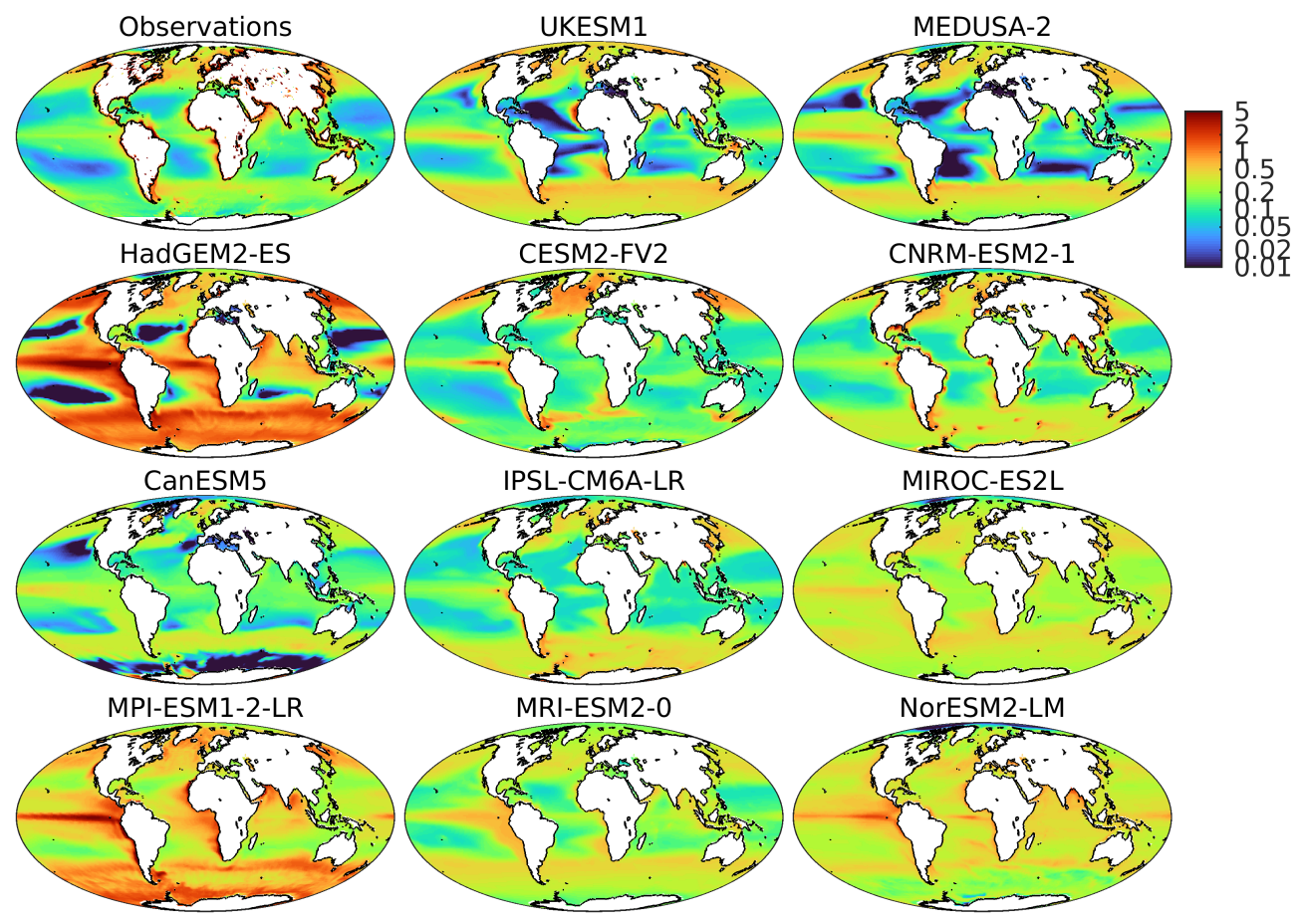

Figure S23. Intercomparison of annual mean surface chlorophyll concentration (CMOR variable chı) between observed (top row, left), UKESM1 simulated (top row, centre) and a range of comparable CMIP6 models (rows 2-4). Results from CMIP5's precursor to UKESM1, HadGEM2-ES (Jones et al., 2011; row 2, left) and MEDUSA-2 (Yool et al., 2013; top row, right) are shown for comparison. Chlorophyll concentration in $\mathrm{mg} \mathrm{chl} \mathrm{m}^{-3}$. 

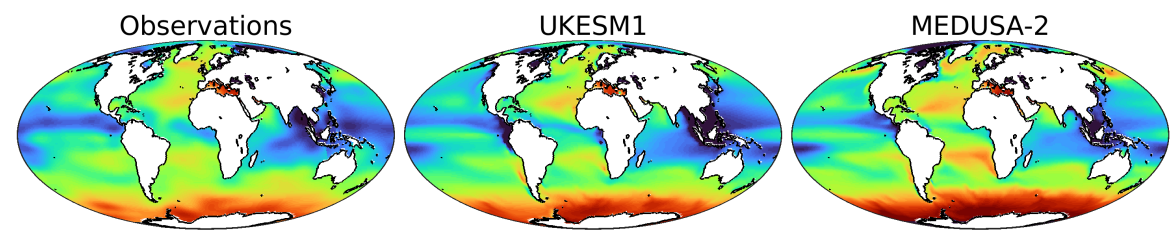

2200

HadGEM2-ES

CESM2-FV2

CNRM-ESM2-1

2000
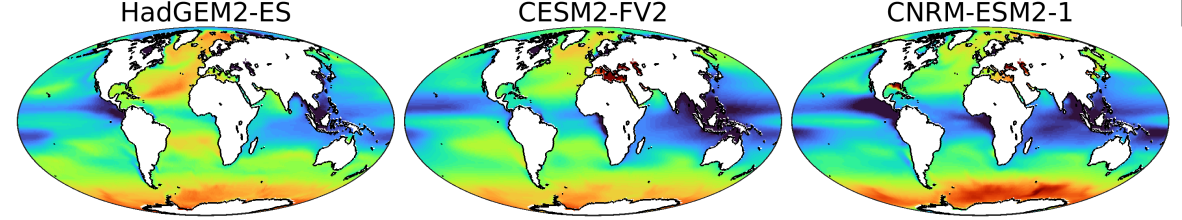

CanESM5

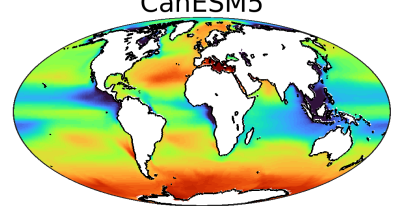

IPSL-CM6A-LR

MIROC-ES2L
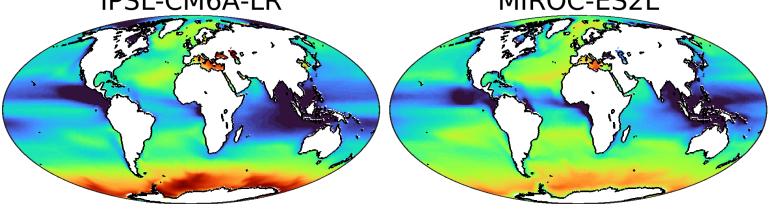

MPI-ESM1-2-LR

MRI-ESM2-0

NorESM2-LM
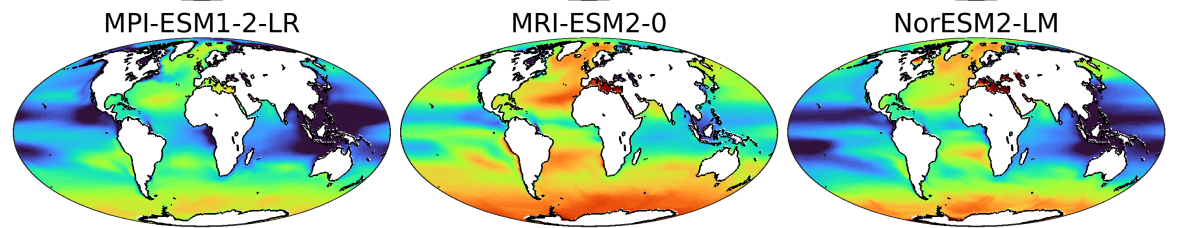

Figure S24. Intercomparison of annual mean surface dissolved inorganic carbon concentration (CMOR variable dissic) between observed (top row, left), UKESM1 simulated (top row, centre) and a range of comparable CMIP6 models (rows 2-4). Results from CMIP5's precursor to UKESM1, HadGEM2-ES (Jones et al., 2011; row 2, left) and MEDUSA-2 (Yool et al., 2013; top row, right) are shown for comparison. DIC concentration in $\mathrm{mmol} \mathrm{C} \mathrm{m}^{-3}$. 


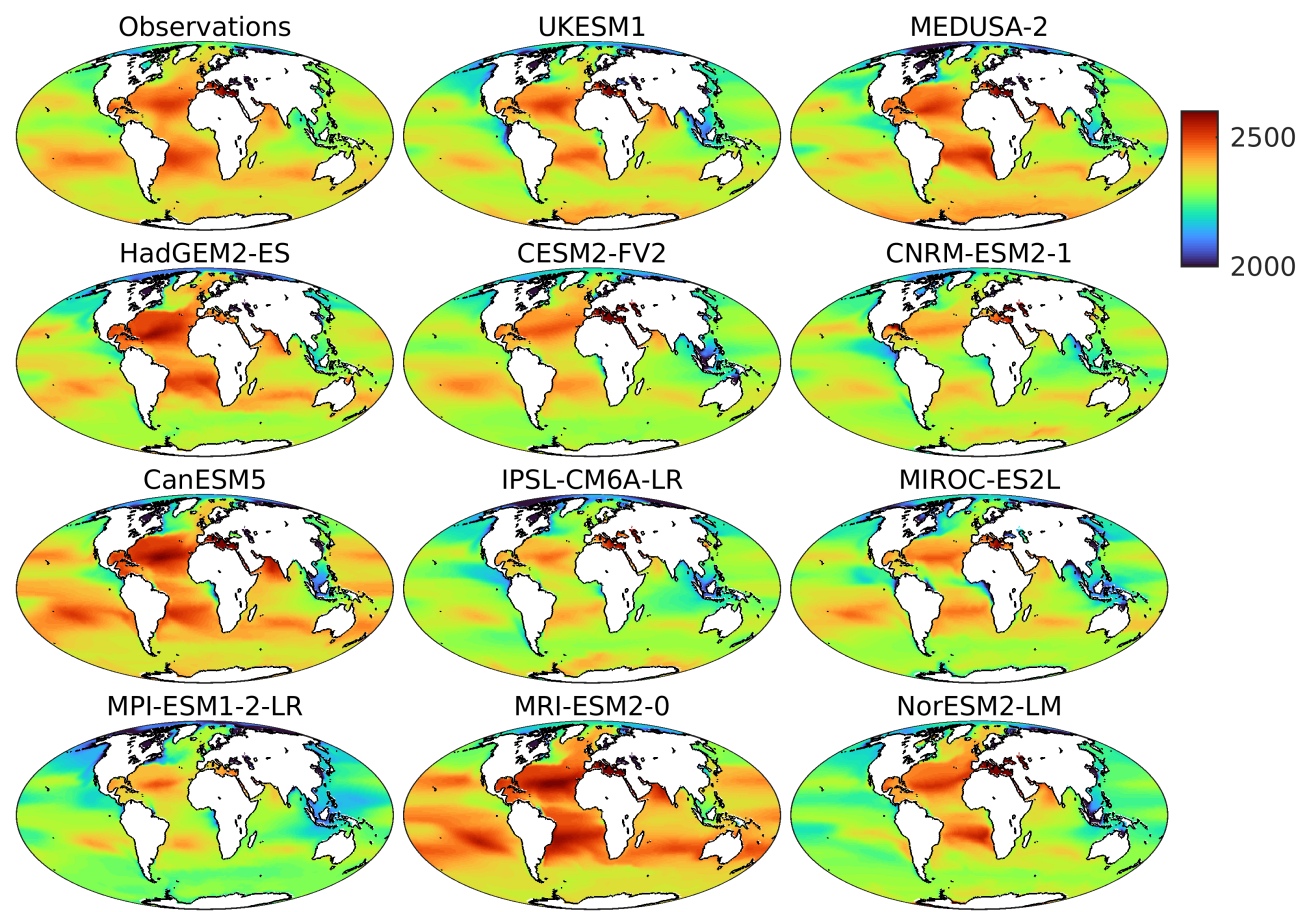

Figure S25. Intercomparison of annual mean surface alkalinity (CMOR variable talk) between observed (top row, left), UKESM1 simulated (top row, centre) and a range of comparable CMIP6 models (rows 2-4). Results from CMIP5's precursor to UKESM1, HadGEM2-ES (Jones et al., 2011; row 2, left) and MEDUSA-2 (Yool et al., 2013; top row, right) are shown for comparison. Alkalinity in meq $\mathrm{m}^{-3}$. 


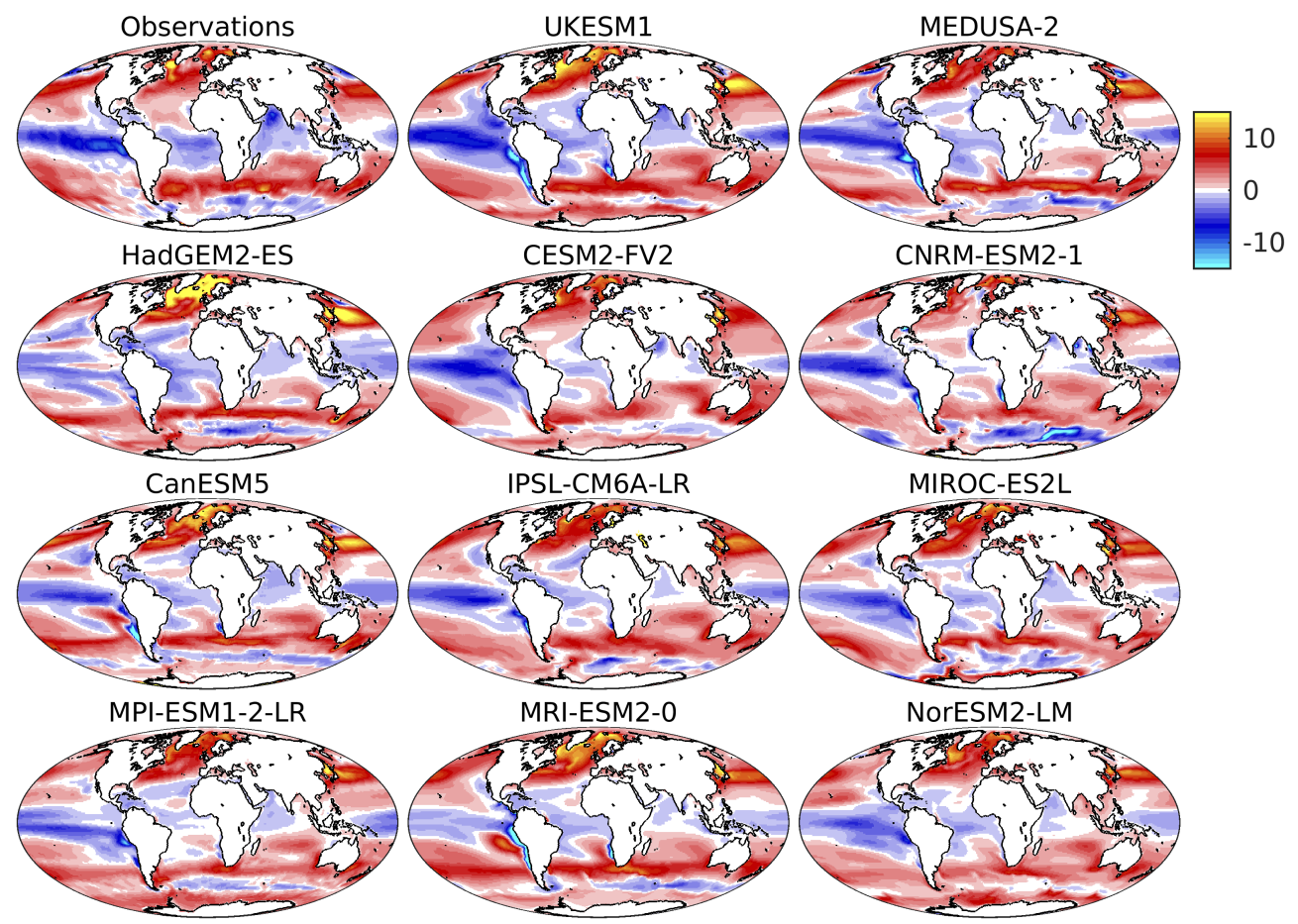

Figure S26. Intercomparison of annual mean air-sea $\mathrm{CO}_{2}$ flux (CMOR variable fgco2) between observed (top row, left), UKESM1 simulated (top row, centre) and a range of comparable CMIP6 models (rows 2-4). Results from CMIP5's precursor to UKESM1, HadGEM2-ES (Jones et al., 2011; row 2, left) and MEDUSA-2 (Yool et al., 2013; top row, right) are shown for comparison. Red / blue colours respectively indicate flux into / out of the ocean. $\mathrm{CO}_{2}$ flux in $\mathrm{mmol} \mathrm{C} \mathrm{m}{ }^{-2} \mathrm{~d}^{-1}$. 


\begin{tabular}{cccc}
$\#$ & Run ID & Branch point & Ensemble ID \\
\hline 0 & u-aw310 & - & - \\
1 & u-az513 & 170 y & r5i1p1f2 \\
2 & u-az515 & $200 \mathrm{y}$ & r6ilp1f2 \\
3 & u-az524 & 145 y & r7i1p1f2 \\
4 & u-bb075 & $110 \mathrm{y}$ & r4i1p1f2 \\
5 & u-bb277 & $710 \mathrm{y}$ & r8i1p1f2 \\
6 & u-bc179 & $400 \mathrm{y}$ & r1i1p1f2 \\
7 & u-bc292 & $315 \mathrm{y}$ & r2i1p1f2 \\
8 & u-bc370 & $270 \mathrm{y}$ & r3i1p1f2 \\
9 & u-bc470 & $435 \mathrm{y}$ & r9i1p1f2
\end{tabular}

Table S1. The piControl and Historical ensemble members used in this study. Run IDs are the formal job identification tags of the ensemble members on local systems, and can be used to access full model outputs on the MASS archive system. The branch points indicate the time points of the piControl simulation (run \#0 above) from which model states were taken to initialise the ensemble members. The ensemble IDs are the experimental variant identifiers used in the ESGF. Note that the table is ordered by run ID and not branch point time. 


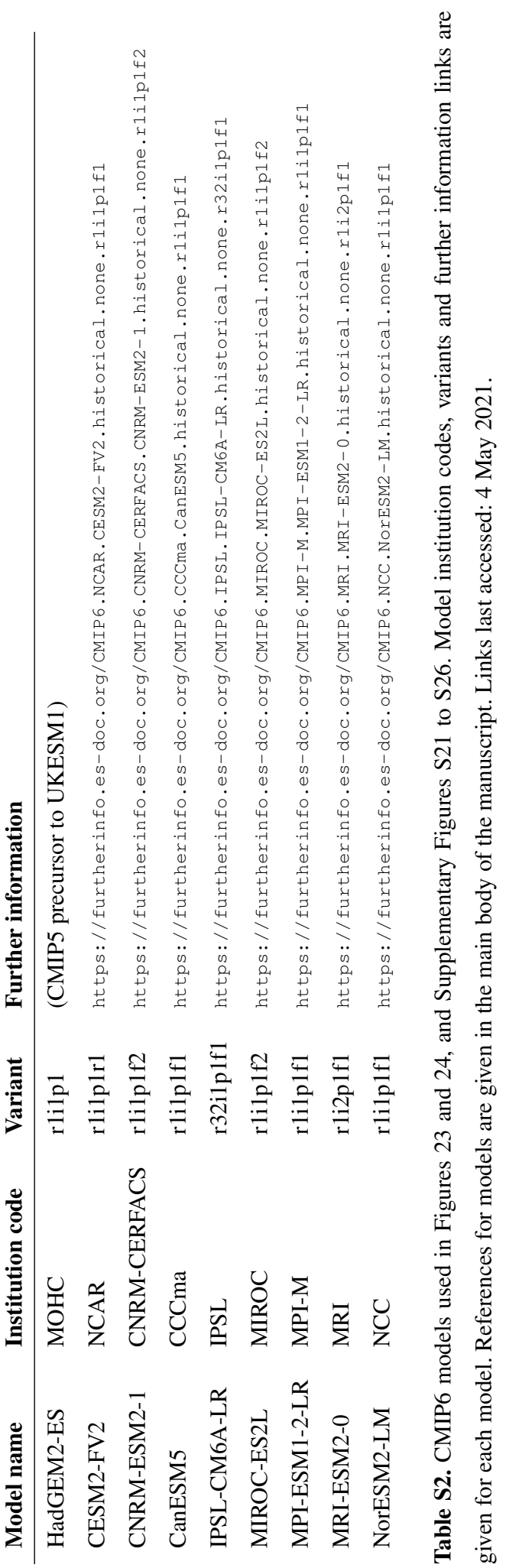

